\title{
Enhanced UDP-Galactose:Glycoprotein Galactosyl Transferase Activity in Cultivated Skin Fibroblasts from Patients with Cystic Fibrosis and Its Possible Relationship to the Pathogenesis of the Disease
}

\author{
(i. J. S. RAO, (IRIITA SPELLS. ANI) HIENRY I. NADLLR: \\ Disision of Genetics. C'hildren's Memorial Hospital, Department of Pediatrics. Northwestern University Medical \\ School. (hicago, Illinois, USA
}

\begin{abstract}
Summary
Homogenates of cultivated skin fibroblasts derived from patients with cystic fibrosis had a higher level of UDP-galactose:ovalbumin galactosyl transferase activity compared to fibroblasts derived from control subjects. The activity in control subjects was $1.82 \pm 0.43 \mathrm{nmol}$ galactose transferred $/ \mathrm{hr} / \mathrm{mg}$ protein, whereas the activity in fibroblasts of patients was $2.95 \pm$ 0.77. The difference was significant at $P-0.01$. Activity in the fibroblasts of obligate heterozygotes was $2.15 \pm 0.60$. The difference between the activities in fibroblasts of heterozygotes and patients was significant at $P<0.05$. The activity in control fibroblasts could be enhanced by basic polypeptides like polylysine, polyarginine, histone, and protamine but not by neutral or acidic polypeptides. Fibroblasts from patients released significantly higher amounts of a soluble form of the enzyme activity into the culture medium than control fibroblasts.
\end{abstract}

\section{Speculation}

The enhanced UDP-galactose:ovalbumin galactosyl transferase observed in fibroblasts of patients with cystic fibrosis may explain many of the abnormalities observed in cystic fibrosis, namely, enhanced glycoprotein secretion, elevated levels of calcium in mucous secretions and obstruction of ducts. The mechanism of enhanced activity is unknown; however, if the primary defect lies in defective $\alpha_{z}$-macroglobulin-protease complexes, the resulting deficient proteolytic activity could generate the "factors" previously identified in the disease. These "factors" may interact with UDP-galactose:glycoprotein galactosyl transferase in a manner similar to that observed with the model polypeptides employed in this study, enhancing its activity.

Cystic fibrosis (c $\mathrm{F}$ ) is an atutosomal recessive disorder associated with elevation of sweat electrolytes and protein in secretions of lung tissues and salivary gland (15). A common mechanism which can account for celevation of both electrolytes and proteins is not vet known. Mangos and coworters $(17,18)$ have reported the presence of cattionic "factors" inhibitory to sodium reabsorption in sweat and salivat of paticnts with ( $F$. The inhibitory effect was mimicked by a number of cationic polymers such as polylysine. The elevation of sodium levels in steat and salival "as thought to be related to the inhibition of sodium reabsorption by the glands.

louisot et al. (16) observed that activity of glyeosyl transferances. which are involved in the hiosynthese of glveoproteins. were elevated in lung tissue preparations from (') paticnts. The mechanism of the clevation of the activity was not investigated in detail.

It is of interest that canine tracheal UIDP-galactose:glycoprotein gatactosy transferase activity is enhanced by many hasic molecules, including poly-l-lysine and histone (2). Therefore, it is tempting to suggest that the lung tissue preparations from ( $\mathrm{F}$ paticnts employed by louisot et al. (16) might have contained some basic molecules similar to the salivary and swe at "factors" which might have activaled the glycosyl transferases.

In order to determine whether the elevation of glycosyl transferase activity is a generalized phenomenon. the activity of UDP-galactose:glycoprotein galactosyl transferase in cultivated skin fibroblasts from patients with $(\mathrm{F}$ and heterozgotes has been compared to control fibroblasts. The results demonstrated a significant clevation of UDP-galactose:glycoprotein galactosyl transferase in fibroblasts derived from patients with (F. A possible mechanism for the elevation of activity and its implications for the pathogenesis of ( $F$ are discussed.

\section{MATLRIALS AND MITHODS}

Uridine diphosphate-galactose $\left(\mid U^{-1}\left(C^{\prime} \mid\right.\right.$ galactose $)$ was obtained from New England Nuclear. Boston. Mass. Uridinc diphosphate-galactose (UDP-gal), ovalbumin (crystalline, saltfrec), $\quad N$-hydroxyethylpiperatzine $\quad N^{\prime}$-2-ethanesulfonic acid (Hepes). poly-L-arginine (mol. wt. $45.00(0)$. poly-L-Iysine hydrobromide (grade iI. mol. wt. $85.00(0)$, protamine sulfate, and histone were obtained from Sigma (hemical company. St. louis, Mo. Copoly-1 -I ys:I-Tyr (1:1) was obtained from Miles Laboratories. Elkhart. Ind. All other chemicals were of the best commercial grade avitilable.

Human skin fibroblasts were cultivated from skin biopsies of patients with $(\mathrm{F}$, obligate heterozygotes, and control subjects hy standard procedures (21). Skin biopsies were obtained with informed consent under the guidelines of the Department of Health, Education and Welfare and with the approval of the Human Ethics and Research (ommittec of The Childrens Memorial Hospital. The fibroblasts were grown in minimal essential medium containing 15\% fetal calf serum in the presence of penicillin, streptomycin. and fungizone, harvested by trypsinization. and used in the experiments. The cells were suspended in $10 \mathrm{mM}$ Hepes buffer. pH 7.0, and homogenized for $1 \mathrm{~min}$ by sonication (9). The microtip of the sonifier (Heat SystemsUltrasonics. Inc.. model W/8.5. Plainview. N.Y.) was set at full speed and the suspension was chilled in an iec water mixture. The whole homogenate was used in most of the experiments immediately or was stored at -10 for future use. Storage for at least 2 months did not affect the assatys. 
UDP-gal:glycoprotein galactosyl transferase (transferase) was assayed by a modification of the procedure of Freilich et al. (12). The reaction mixture for the assay in a volume of $0.025 \mathrm{ml}$ contained $7.3 \mu \mathrm{M}$ UDP-gal $\left(\left|U-{ }^{14} \mathrm{C}\right|\right.$ galactose $)(84.000 \mathrm{cpm}) .10$ $\mathrm{mM} \mathrm{Mn} \mathrm{n}^{++}$. (0.1\% Triton, $0.5 \mathrm{mg}$ ovalbumin dissolved in $10 \mathrm{mM}$ Hepes, and fibroblast homogenate corresponding to $10-20 \mu \mathrm{g}$ protein. The reaction was initiated by the addition of the homogenate. The assay tubes were covered with Parafilm and incubated at $37^{\circ}$ for $10 \mathrm{~min}$. The reaction was stopped by the addition of $1.0 \mathrm{ml}$ phosphotungstic acid in $0.5 \mathrm{M} \mathrm{HCl}$ followed by $1.0 \mathrm{mg}$ bovine serum albumin. which acted as a carrier. The precipitate was separated by centrifugation at $4000 \times g$ for 10 min. The pellet was washed with $3 \times 1.0 \mathrm{ml} 5 \%$ trichloroacetic acid and dissolved in $0.2 \mathrm{ml} 2 \mathrm{~N} \mathrm{NaOH}$. Radioactivity in a 0.1 $\mathrm{ml}$ aliquot of the $\mathrm{NaOH}$ digest was determined in a liquid scintillation spectrometer (Mark II. Nuclear Chicago. Des Plaines, Ill.). The counting vials were cooled for $8 \mathrm{hr}$ in the dark before counting. Under these conditions, the alkalinity of the digest did not adversely affect the measurements. Assays were routincly carried out in duplicate. Blanks omitting ovalbumin were run with each incubation. Standard UDP- $\left[U^{-14} \mathrm{C}\right]$ galactose was always run with each counting series.

To study transferase activity in culture medium, fibroblasts were grown to confluency in $7.5-\mathrm{cm}^{2}$ flasks. The medium was discarded and the cell monolayer was gently washed with $3 \times 30$ $\mathrm{ml}$ Puck's saline: $5 \mathrm{ml}$ minimal essential medium supplemented with penicillin. fungizone, and streptomycin were then added. The flasks were incubated at $37^{\circ}$ and the medium was collected and centrifuged at $4000 \times g$ at $4^{\circ}$ for $15 \mathrm{~min}$ and the supernatant saved. In some cases, the medium was concentrated to $25 \%$ the original volume by dialysis against Ficoll. Transferase activity in the medium and the concentrates was assayed as described above. Transferase activity is expressed as nanomoles of galactose transformed per hr per me protein or per culture.

\section{IDENTIFICATION OF PRODUC"I}

For purposes of the assay, it was necessary to demonstrate that galactose was transferred from UDP-gal to ovalbumin rather than endogenous acceptors. Therefore, the following experiment was carried out. The standard incubation employed for the assay of the transferase was terminated by the addition of an equal volume of $100 \mathrm{mM} \mathrm{Na} \mathrm{N}_{2}$ EDTA. Two volumes of a mixture of $40 \%$ sucrose and $0.4 \%$ sodium dodecyl sulfate were added. The entire mixture was resolved by electrophoresis in Tris buffer, at $\mathrm{pH} 8.9$. containing $0.1 \%$ sodium dodecyl sulfate in 10$\mathrm{cm}$ polyacrylamide rods at $2 \mathrm{~mA}$ current (32). The electrophoresis was stopped when the tracking dye reached $0.5 \mathrm{~cm}$ from the bottom edge of the tube. The gels were sliced into $4-\mathrm{mm}$ sections and oxidized with $0.2 \mathrm{ml} 30 \% \mathrm{H}_{2} \mathrm{O}_{2}$ overnight at $50^{\circ}$ in capped scintillation vials $(20)$. A small vial containing $0.2 \mathrm{ml}$ hyamine base was also kept in the vials to trap the CO.z evolved. After heating. the vials were cooled and shaken to enable the hyamine to mix with the oxidized gels. Radionactivity in the vials was determined by liquid scintillation spectrometry at $20 \%$ efficiency. A control incubation mixture not containing ovalbumin was also run. Another gel containing ovalbumin as the marker was run simultaneously and stained with Coomassie hlue. Data were analyzed for statistical significance by the Student $t$-test (1).

\section{RESUITS}

\section{ASSAY OF TRANSFERASE: ACTIVITY IN CONTROI. FIBROBI ASTS}

Cultivated human skin fibroblasts contain UDP-gal: glycoprotein transferase which can transfer galactose from UDP-gal to ovalbumin. The product of the reaction was identified as galactose covalently linked to ovalbumin as shown by polyacrylamide disc gel electrophoresis (Fig. 1). Two peaks of radioactivity are observed in the gels. The first peak, which is present in both blanks and in the incubation mixture containing ovalbumin. is close to the dye front and represents free UDPgal. The second peak. corresponding to the position of ovalbumin (which moves similar to labeled ovalbumin in gels containing sodium dodecyl sulfate), is present only in the gels loaded with the incubation mixture containing ovalbumin.

Transferase activity is linear up to 10 min at $7.3 \mu \mathrm{M}$ UDP-gal concentration (Fig. 2A); linear up to $0.030 \mathrm{mg}$ protein (Fig. $2 B$ ), and optimal at $\mathrm{pH} 7.0$ in Hepes buffer (Fig. 2('). Therefore, all the incubations have been carried out for $10 \mathrm{~min}$ at $\mathrm{pH} 7.0$ at $0.10-0.020 \mathrm{mg}$ protein.

Under these conditions, the blanks (in the absence of ovalbumin) gave approximately $200 \mathrm{cpm}$ whereas in experimental as says, $1200-2000 \mathrm{cpm}$ were observed, depending upon the protein concentration. Although the assay was linear for longer periods at $1.0 \mathrm{mM}$ UDP-gal, the sensitivity of the assay was decreased because of the dilution of the substrate by nonradioactive UDP-gal. Since the emphasis in this study is on discrimination between the levels of transferase in control cells and cells from patients with $C F$, the more sensitive conditions, i.e.. at 7.3 $\mu \mathrm{M}$ UDP-gal, have heen employed. In one experiment. $1 \mathrm{ml}$ fresh homogenate of control fibroblasts was centrifuged at $100.000 \times g$ at $4^{\circ}$ for $30 \mathrm{~min}$ and $80 \%$ of the transferase activity could he recovered from the pellet.

The specific activity of transferase was not significantly af-

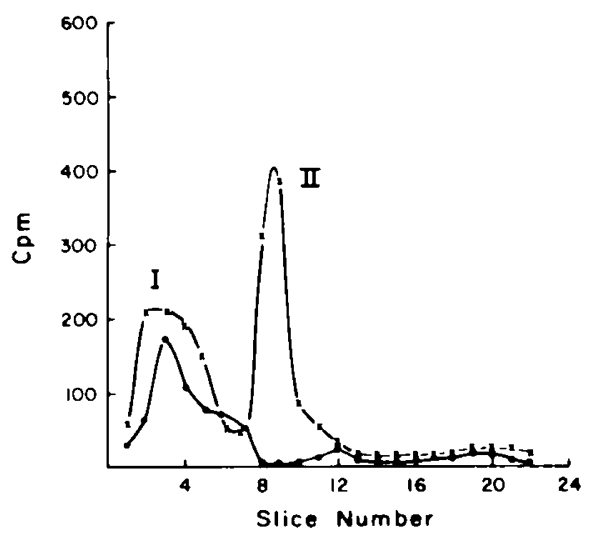

Fig. 1. Identification of the product of the transferase reaction. The gel slices are numbered from the bottom of the gel. - - reaction mixture containing no ovalbumin; $\times-\times$ : reaction mixture containing ovalbumin.

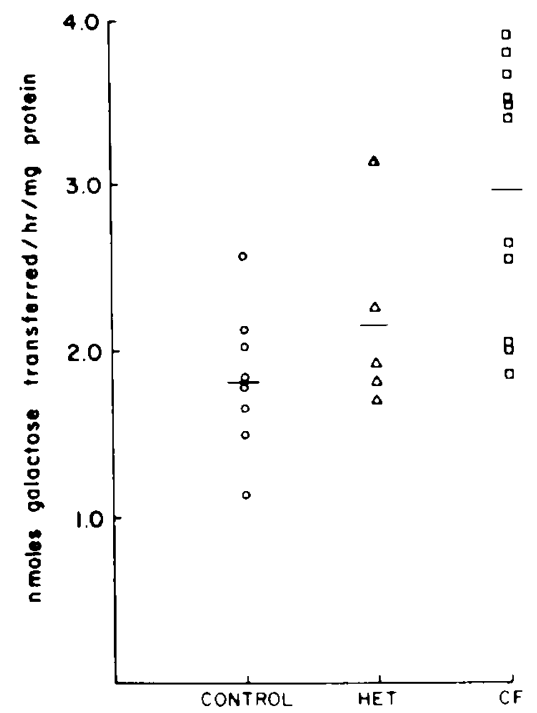

Fig. 2. Transferase activity in fibroblast homogenates derived from control subjects ( CONTROI.), obligate heterozygotes $(H E T)$, and paticnts with cystic fibrosis $(C F)$. 
fected by the duration of time maintained in culture or by cell density. The cells were routinely harvested at confluency for assay.

ASSAY OF TRANSFERASE: IN FIBROBLASTS DERIVED FROM CONTROL SUBJECTS, OBLIGATE HETEROZYGOTLS, AND PATIFNTS WITH CF

The results of assays of transferase in fibroblasts from 8 control subjects, 5 obligate heterozygotes, and 11 patients with cystic fibrosis are shown in Figure 3. These assays were carried out at $7.3 \mathrm{mM}$ UDP-gal. The control cells had activity of $1.82 \pm$ 0.43 , the cells from CF patients had 2.95 \pm 0.77 , and heterozygotes hald $2.15 \pm 0.60$. The difference between control subjects and patients was significant at $P<0.01$; between patients and heterozygotes the difference was significant at $P<0.05$. In all of these experiments, a standard control homogenate was always assayed as an internal control and the reproducibility of the activity in this homogenate was within $10 \%$. In other lines, the reproducibility of the assaly was within the range of $5-15 \%$ at successive passages in culture. All cells were analyzed within 15 20) passages in culture. Similar experiments using $1 \mathrm{mM}$ UDP-gal in four control lines and four lines from patients with ( $F$ demonstrated activity of $1.83 \pm 0.29$ and $3.75 \pm 1.22$. respectively. This difference was also significant at $P<0.05$. Assays in the absence of ovalbumin did not reveal any difference between transferase levels in control subjects and patients.

\section{IFFFE(T OF POI.YMERS ON TRANSFERASH}

The effect of a series of polypeptides on transferase in a control fibroblast homogenate. tested at a $1.0 \mathrm{mM}$ UDP-gal concentration, is shown in Table 1 . It is clear that the positively charged polypeptides, poly-L-arginine, poly-L-lysine, protamine, histone, and copoly-L-Lys:L-Tyr (at pH 7.0). enhance the activity. However, poly-L-glutamic acid, which is acidic or polyL-hydroxyproline, which is neutral, did not produce a comparable level of enhancement. The enhancement by poly-L-lysine and poly-L-arginine followed a dose-response relationship.

\section{TRANSFERASE: ACTIVITY IN SE:RUM-FREE MEDIUM FROM} CULTURES OF FIBROBLASTS

Serum-free medium, obtained after contact with confluent cultures at $37^{\circ}$. contained significant amounts of transferatse activity. The medium at the beginning of incubation did not contain any activity; however, activity accumulated (Fig. 3) as a function of time and leveled off at $72 \mathrm{hr}$. The exact nature of this activity is not clear, but it is heat labile and nondialyzable. Newly subcultured cells grown in the presence of serum-free medium contained low levels of activity. In addition, no activity could be detected in the culture medium under these conditions.

ASSAY OF ACTIVITY IN (UITURE MEDIUM ()F FIBROBI.ASIS FROM CONTROI. SUBJECTS, PAIIENTS WITH ('F, AND HETLROZYCiOTHS

Assay of transferase activity in serum-free medium collected after $48 \mathrm{hr}$ in contact with confluent cells showed that $\mathrm{CH}$ fibroblasts released a greater amount of activity than control cells (Fig. 4). The mean activity was $2.00 \pm 0.97$ in control culture media and $4.59 \pm 0.57$ in $(\mathrm{F}$ culture media. This difference was significant at $P<0.01$. Medium from cultures of two heterozygotes had activities similar to control, and medium from two other heterozygote cultures had levels of activity comparable to those derived from patients with CF. Similar differences in activity between control and (F fibroblasts could be demonstrated when the activity was expressed in terms of protein content of the fibroblasts rather than the volume of culture medium.

\section{DISC USSION}

The experiments reported in this paper demonstrate that UDP-gal:glycoprotein galactosyl transferase activity is signifi-

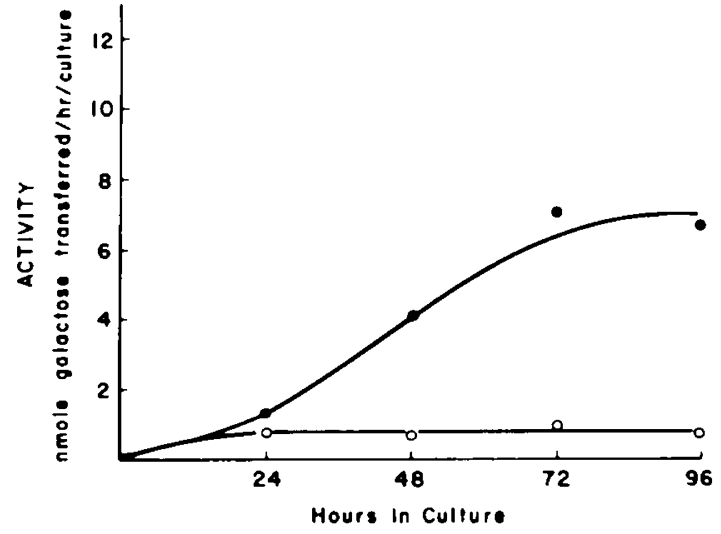

Fig. 3. Transferase activity in fihroblast homogenates and serum-free culture medium assilyed as a function of time. homogenates; activity in the medium.

Table 1 . Effect of polymers on transferase activity in a control fibroblast homogenate

\begin{tabular}{|c|c|c|c|}
\hline Polymer & $\begin{array}{c}\text { Concen- } \\
\text { tration. } \\
\mathrm{mM}\end{array}$ & Activity & $r$ \\
\hline & & 1.6 .3 & 100 \\
\hline ace & 0.01 & 4.95 & 300 \\
\hline & 0.1 & 3.04 & 187 \\
\hline & 0.1 & 3.45 & 212 \\
\hline & 0.1 & 2.93 & 180 \\
\hline ne:l-tyrosine $(1: 1)$ & 0.1 & 2.48 & 152 \\
\hline ic acid & 0.1 & 1.72 & 106 \\
\hline xyproline & 0.1 & 1.89 & 116 \\
\hline
\end{tabular}

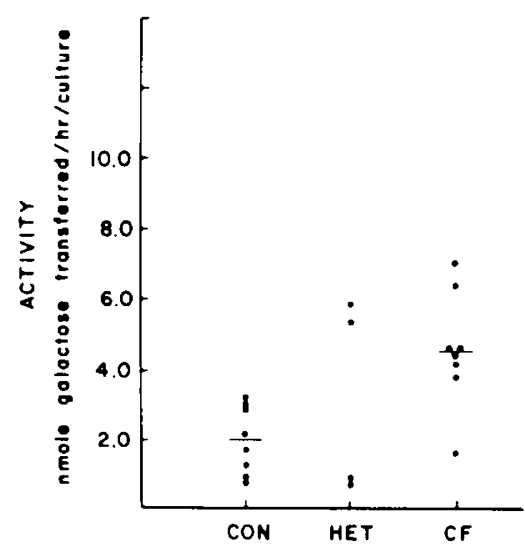

Fig. 4. Transferalse activity in serum-free medium in cultures of tibrohlasts derived from patients with eystic fibrosis $(C F)$, heterozygotes $(H E T)$, and control subjects $(C O N)$.

cantly elevitted in fihroblasts and culture medium derived from patients with ( $F$. This clevation of activity in fibroblasts is not due to the higher level of an endogenous glycoprotein acceptor.

The mechanism of elevation of activity in fibroblasts is not clear at present. Preliminary studies of kinetic parameters such as $K_{m}$ and $V_{\text {mas }}$ for UDP-gal, ovalbumin, and $\mathrm{Mn}^{\prime \prime}$ show that the $\mathrm{Km}$ for $\mathrm{Mn}^{+}$" in ( F fibroblasts is $1 \mathrm{mM}$ whereas it is $2.5 \mathrm{mM}$ in control subjects. This observation is analogous to the decrease in $\mathrm{Km}$ for $\mathrm{Mn}$ ' observed by Baker and Hillegass (2) in the presence of basic molecules for canine tracheal transferase. It is conceivate that some factor present in the homogenates of $\mathrm{CF}$ fibroblasts interacts with the transferase. reducing its $\mathrm{Km}$ for Mn' +, thereby activating the enzyme.

The mechanism of elevation of activity discharged into the serum-free medium of ( $\mathrm{F}$ fibroblasts is not known. It probably 
represents either a soluble form of the enzyme produced by the fibroblasts or a solubilization of the particulate enzyme under the experimental conditions. Since transferase in serum is a glycoprotein (11), the elevation of the soluble enzyme activity in the medium probably represents a calse of increased synthesis and secretion of glycoprotein and could be the demonstration of such a phenomenon by a nonexocrine cell.

In contrast to our findings of a significant difference between transferase levels in fibroblasts from control subjects and patients with CF. Butterworth (5) found elevated but not statistically different levels in fibroblasts from patients. The differences in experimental conditions in Butterworth's work (5) and the present study are as follows: (/) we have employed whle homogenates in huffer. whereas Butterworth employed microsomal suspensions in sucrose; (2) we have used crystalline ovalbumin in contrast to commercial submaxillary mucin; and (3) we have corrected our data for variations associated with scintillation spectrometry rather than direct counts per min.

The physiologic basis of the elevation of activity in ( $F$ is unknown at present. It is well known that salival (18), serum (4. 30), and culture medium of cells de rived from CF patients (3. 7 ) contain high molecular weight substances which can inhibit sodium reabsorption $(18.26)$ or induce cessation of ciliary beat $(3$. 4.7). These substances contain protein or polypeptide moieties and are all basic at physiologic pH. In addition. synthetic basic polypeptides can simulate some of these effects. Therefore, the enhancement of transferase activity by basic polypeptides, hut not neutral or acidic polypeptides, suggests that ( $F$ cells produce some basic polypeptide or polypeptides similar to the "factors" which interact with the transferase enhancing its activity. The enhancement might be nonspecific in that other transferases like manosyl and glucosyl transferases may also be elevated, as suggested indirectly by the datat of louisot et al. (16).

The enhancement of transferase activity provides a physiologic basis for understanding the elevation of glycoproteins in mucous secretions of CF patients. The elevation of glycosyl transferases could result in an elevation of net synthesis of glycoproteins. The elevated levels of glycoproteins may be secreted hy mechanisms operating in normal cells like stimuluscoupled secretion (27) or membrane degranulation (6). It is of interest that the activity we hatve studied and that Louiset et al. (16) have studied resides in the particulate fraction. These enzymes are known to reside in the Golgi apparatus. which has long been known to be involved in glycoprotein synthesis and secretion. Thus, an elevation of glycosyl transferase activity could be a reflection of hyperactivity of this secretory organelle.

The enhancement of transferase activity has a bearing on other observations related to cystic fibrosis. The carbohydrate chains of many glycoproteins have sialic acid at their termini. Addition of a greater number of galactose residues could provide more sites for the addition of other sugars and sialic acids. Alternatively, the activity of other transferases may also be enhanced. as suggested by the results of Louisot at al. (16). resulting in a net increase of sialic acid residues. It is of interest that sialic acid incorporation into glycoproteins of $(F$ fibrohlasts has been shown to be significiantly elevated (19). Furthermore. preliminary experiments in our laboratory have indicated that sialic acid levels in fibroblasts of $C F$ patients are significantly clevated. The strongly acidic carboxyl group of sialic acid (pK 2.6) can preferentially react with anionic dyes like toluidine blue O. producing metachromatic granules to a greater extent in many $C F$ fibroblast lines, as reported in the literature ( 8 ). Therefore, the enhancement of transferase provides a hypothetical but rational basis for the production of metachromasia.

The enhanced levels of sialic acid could also provide more sites for the hinding of calcium. Sialic acid-bound calcium, being less exchangeable $(14)$, would he bound tightly. It hecomes unavailable for reabsorption by calcium transport mechanisms and thus. its net level in mucous secretions hecomes elevated. Calcium. because of its divalent nature. will form intermolecular crosslinks between glycoproteins (13) and between mucins (10). producing insoluble polymers (10). Under physiologic conditions, the polymers formed in the presence of elevated calcium may result in the formation of mucous plugs, therehy producing the classic pathologic and physiologic abnormality in C $F$. namely organ obstruction.

It is of interest that the "factors" reported from tissues and fluids derived from ( $\mathrm{C}$ patients are all cationic at physiologic $\mathrm{pH}$. contain protein or polypeptide entities $(3.4,7.18)$, and are similar to polylysine and other cattionic polymers in their effects in experimental systems. These "factors." because of their cationic polypeptide nature, are ideal substrates for proteclytic enzymes of specificity similar to trypsin. Rato and Nadler (2225) have documented previously a deficiency of proteolytic activity in saliva and plasma of patients $w$ ith $C F$ and have postulated that such a deficiency could account for the elevation of the levels of the "factors." More recently. Wilson and Fudenberg (31) and Shapira et al. (28, 29) have demonstrated that the deficiency of proteolytic activity arises from abnormal complex formation between $\alpha_{2}$-macroglobulin and endopeptidases. Recently. work in our laboratory in collaboration with Dr. Shapirat has suggested distinct molecular differences in normal and $C F$ $\alpha_{2}$-macroglobulin. Therefore, the elevation of the cationic polypeptides originating from the abnormalities in the $\alpha_{2}$-macroglobulin-protease complexes could account for the various abnormalities associated with cystic fibrosis. The interrelationships discussed above have been integrated schematically in Figure 5.

\section{(CONCI.USION}

UDP-gal:ovalbumin galactosyl transferase activity is significantly enhanced in cultivated skin fibroblasts of patients with cystic fibrosis. This enhancement of activity can be simulated by the addition of basic polypeptides to homogenates of control fibroblasts. The enhanced transferase activity may be due to the interaction of some basic "factors" present in the CF cells with the transferase. The presence of the factor may be caused by a deficiency of proteolytic activity. In addition. (F fibroblasts also refease a soluble form of transferase activity into serum-free medium to a greater extent than control cells. This phenomenon

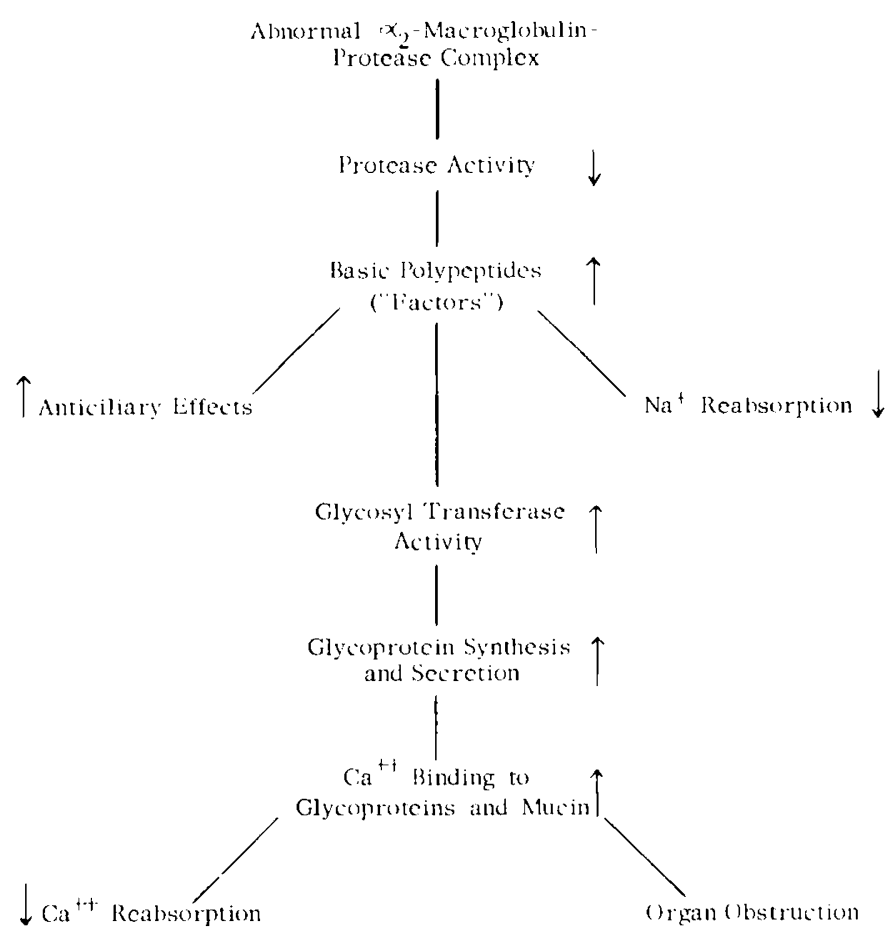

Fig. 5. Hypothesis relating the defective $\alpha_{2}$-macroglobulin-protease complex to abnormalities reported in cystic fibrosis. $\uparrow$ : increase; $\downarrow$ : decrease. 
may be a reflection of increased glycoprotein synthesis and secretion.

A hypothesis relating the deficiency of proteolytic activity in cystic fibrosis. reported earlier by us, and the enhanced transferase activity to abnormalities in cystic fibrosis is presented.

\section{REFEREN('ES AND NOTES}

1. Armitage, P.: Statistical Methods in Medical Research. p. 105 (John W'iley \& Sons. New York, 197.3).

2. Baker, A. P.. and Hillegass, I. M: Enhancement of UDP-galactone: Mucin galactesyltransferase activity by spermine. Arch. Biechem. Biophys., 16.5. $547(1074)$

3. Bowman. B. H. Barnett, D. R.. Matalon, R., Danes, B. S.. and Bearn, A. (i.: Cystic fibrosis: fractionation of fibroblast media demonstratting ciliary inhibition. Proc Natl. Acatd Sci. U. S. A. 70 : 548 (1973).

4. Bowman. B. H. Mc oombs. M. I... and I.nckhart. I. H.: Cystic fibrosis: Characterization of the inhibitor to ciliary action in oyster gills. Science. 167: $871(1970)$.

5. Butterworth J.: Properties of microsomal glycoprotein galactosy: tramsferase of cultured human fibroblasts in relation to cestic fibrosis. Clin. (him. Acta. 56: $159(1974)$

6. Conod, F. J.. Conover, J. H.. and Hersehhorn, K.: Demonstration of human leukocyte degranulation induced by sera from homozygotes and heterezygotes for cystic fibrosis. Pediat. Res.. 4: 725 (1975).

7. Conover, J. C.. Beratis, N. G.. Conod, E. J., Ainhender, F... and Hirschhorn. K.: Studies on ciliary dyskinesia factor in cystic fihrosis. II. Short term leukocyte cultures and long term lymphoid lines. Pediatl. Res., 7: 224 (1973)

8. Danes. B. S., and Bearn. A. (;.: A genetic cell marker in cystic fihrosis of the pancreas. Lancet. $i: 1061(1968)$

9. Deppert. W.. Werchau. H. and Walecr. (;.: Defferentiattion hetween intracellular and cell surface glycosyl transferases: (ialactosyl transferase activity in intact cells and in cell homengenates. Proc. Natl. Acad. Sci. l1. S. A. .7/ $3068(1974)$

10. Forstner, J. F., and Forstner, C. G.: Fffects of ealcium on intestinal mucin: implications for cystic fibrosis. Pediat. Res.. 10: $6(19)(1976)$.

11. Fraser. 1. H. and Mookerjea. S.: Studies on the purification and properties of UDP-galactose:glycoprotein galictosyltransferase from rat liver and serum. Biochem. J., 156:347(1976)

12. Freilich, I.. S. Richmond, M. I... Reppucei, A. C.. Jr.. and Silbert. J. I .. A micro method for simultaneous determination of galatetesyltransferane and 5 -nucleotidase activition in cell fraction. Biochem. J. 146: 741 (1975)

13. Gugler, E.. Pallavicini. C. J.. Swerdlow. H.. and di Sant Agese. P. A.: The role of calcium in submaxillatry silliva of pittents with cystic fibrosis. I. Pediat. . 7l: $585(1967)$

14 Langer, G. A Frank, J. S. Nudd, I. M.. and Seraydarian. K.: Siatle acid Effect of removal on calcium exchangeathility of cultured heart cells. Science, $19.3: 1013(1976)$.

15. Lobeck. ( C.: (ystic fibrosis. In: J. B. Stanhurv. J. B. Wyngaarden. and I) S. Frederickon: The Metaholic Basis of Inherited Disease, pp. 1605-1621 (Mc(irau-Hill Book Co.. New York, 1972).

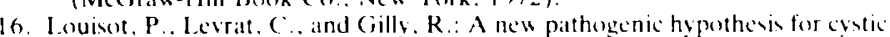

fibrosis: Hyperactivity of glycosyl transferases at the microsomal level. (Tin. ('him. Acta. 48: 373 (1973).

17. Mangos. J. A.. and MeSherry. N. R.: Sodium transport: Inhibitory factor in sweat of patticnts with cystic fibrosis. Science, 158 : 135 (1967)

18. Mangos, J A McSherry. N. R.. and Benke. P. J.: A sodium transport inhihitor facter in the saliva of patients with cystic fibrosis of the pancreas. Pediat. Res.. 1: $436(1967)$

19. Matalon. R.. and ifonclli, J. A.: Acctate uptake by cultured fibroblasts from patients with cystic fibrosis. Fed. Proc . 35: 16.39/1441 (1976)

20. Michaliszyn. (i. A., and Meighen. F. A.: Induced polypeptide synthesis during the development of bacterial bioluminescence, J. Biol. (hem.. 25/ $25.31(1976)$

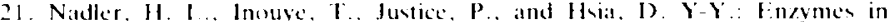
cultivated human kin fibroblasts derived from patients with Down svndrome (mongolism). Nature, 213:1261 (1967).

22. Raw, (i. J. S., and Nadler. H. I... Deficiency of trypsin-like activity in salisa of paticnts with cystic fibrosis. J. Pediat. 80): 573 (1972)

23. Rato, (;. J. S., and Nadler, H. I..: Arginine esterase in cystic fibronis of the pancreas. Pediat. Res., 8: $68+(1974)$.

24. Rate. (;. J. S., and Nadler. H. I..: Deficiency of arginine esterase in cystic fibrosis of the pancreas: Demonstration of the proteolytic nature of the activity. Pediat. Res. 9: $739(1975)$.

25. Rilo, (;. J. S. Ponner. I. A. and Nadler. H. 1..: Deficiency of killikrein activity in plasma of patients with cystic fibrosis. Science, 177: 010 (1972)

26. Schmoyer, l. R., and Baglia. F. A.: ( vatic fihrosis: effect of media from cultured cystic fihrosis fibroblasts on ATPanse activity. Biochem. Biophys Res. Commun.. 58: $1066(1974)$.

27. Schramm, M.: Secretion of macromolecules by exocrine glands. In: J. A Mangos and R. ( . Talamo: Fundamental Problems of cystic Fibrosis athe Related Diseases. pp. 215-228 (Intercontinentitl Medical Bosk Corporattion, New York, 1973).

28. Shapira, I... Ben-Yoseph. Y.. and Nadler. H. I... Decreaned formation of a.z matcreglobulin-proteasc complexes in plasma of patients with cystic fibrosis Biochem. Biophys. Res. (ommun.. 71: 864 (1976).

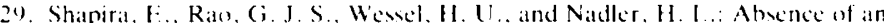
a. - macroglobulin-protease complex in crstic fibrosis. Pediat. Res.. 10: 812 (i976).

30. Spock, A. Heick, H. M. ( .. Cress, H. and logan. W. S.: Abnormal erum facter in patients with cystic fibrosis of the pancreas. Pediat. Res., l: 17.3 (1967).

31. Wilson, (i. B.. and Fudenherg. H. H.: Studien an cystic fibronis using isolecetric focusing. II. Demonstration of deficient protedytic cleatsage of $\alpha_{2}-$ macroglobulin in crstic fibrosin plasma. Pediat. Res.. 10:87 (1976)

32. Work $\mathrm{T} S$ and Work $1 \mathrm{H}$ aboratory Techniques in Biochemisery and Molecular Biology. Vol. 1, pp 34-92 (North Holland Publishing (i).. Amsterdam. 196iy).

3.3. This study was supported by grants from The National lostitutenof Health $A M$ $18+62$. The National Foundation-Narch of Dimes, and the Helen Faty Hunter Trust. Henry 1. Nadler is the Irene Jeinz (iven and John I at Porte (iven Research Professor of Pediatrics. 34. Requests for reprinte should be addressed to: H. L. Hadler, M.D.. ('hildren's Memorial Hospital. $230(0)$

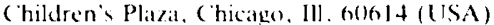

35. Received for publication November 18.1976

36. Accepted for puhlication Fehratury 9. 1977. 